\title{
Validation and clinical implications of the IDSA/ATS minor criteria for severe community-acquired pneumonia
}

\author{
J Phua, ${ }^{1}$ K C See, ${ }^{1}$ Y H Chan, ${ }^{2}$ L S Widjaja, ${ }^{3}$ N W Aung, ${ }^{4}$ W J Ngerng, ${ }^{1}$ T K Lim ${ }^{1}$
}

${ }^{1}$ Division of Respiratory and Critical Care Medicine, Department of Medicine National University Hospital, Singapore; ${ }^{2}$ Biostatistics Unit, Yong Loo Lin School of Medicine, National University of Singapore, Singapore; ${ }^{3}$ Medical Affairs, National University Hospital, Singapore; ${ }^{4}$ School of Health Sciences, Ngee Ann Polytechnic, Singapore

Correspondence to: Professor T K Lim, Division of Respiratory and Critical Care Medicine, Department of Medicine, National University Hospital, 5 Lower Kent Ridge Road, Singapore 119074; mdclimtk@nus.edu.sg

Received 16 January 2009 Accepted 27 March 2009 Published Online First 20 April 2009

\begin{abstract}
Background: The 2007 Infectious Disease Society of America (IDSA)/American Thoracic Society (ATS) guidelines defined severe community-acquired pneumonia (CAP) and recommended intensive care unit (ICU) admission when patients fulfilled three out of nine minor criteria. These criteria have not been validated.

Methods: All patients admitted to our hospital from 2004 to 2007 for CAP were reviewed retrospectively. Patients who fulfilled any IDSA/ATS major criteria for severe CAP at the emergency department (ie, the need for mechanical ventilation or vasopressors) were excluded. The predictive characteristics of the IDSA/ATS minor criteria were compared with those of the Pneumonia Severity Index (PSI) and the CURB-65 score for hospital mortality and ICU admission.
\end{abstract}

Results: 1242 patients were studied (mean age 65.7 years, hospital mortality $14.7 \%$ ). The areas under the receiver operating characteristic curves for the IDSA/ATS minor criteria were $0.88(95 \% \mathrm{Cl} 0.86$ to 0.91$)$ and 0.85 (95\% Cl 0.81 to 0.88 ) for predicting hospital mortality and ICU admission, respectively. These were greater than the corresponding areas for the PSI and the CURB-65 score $(p<0.05)$. The sensitivity, specificity, positive and negative predictive values of the minor criteria were $81.4 \%, 82.9 \%, 45.2 \%$ and $96.3 \%$, respectively, for hospital mortality and $58.3 \%, 90.6 \%, 52.9 \%$ and $92.3 \%$, respectively, for ICU admission. The minor criteria were more specific than the PSI and more sensitive than the CURB-65 score for both outcomes.

Conclusion: These findings support the use of the IDSA/ ATS minor criteria to predict hospital mortality and guide ICU admission in inpatients with CAP who do not require emergency mechanical ventilation or vasopressors.

Community-acquired pneumonia (CAP) is a common disease which frequently leads to hospitalisation and, not rarely, to death. ${ }^{1}$ As a result, clinical prediction rules are often used to determine the prognosis. Patients who are assessed to have moderate and high risks of death are admitted to the general ward and the intensive care unit (ICU), respectively. Such prediction rules assist in the appropriate utilisation of limited hospital and ICU resources. Two commonly used rules are the Pneumonia Severity Index (PSI) and the CURB-65 (confusion, urea, respiratory rate, blood pressure and age) score. ${ }^{2}{ }^{3}$ However, while they are useful in determining which low-risk patients may be discharged home from the emergency department, they-and most other rules to date - are less accurate in determining the patients at the highest risk of death who require ICU admission. ${ }^{2-5}$
Indeed, how severe CAP should be defined remains unclear.

In response, the Infectious Disease Society of America (IDSA) and the American Thoracic Society (ATS) issued guidelines in 2007 which defined severe CAP - and recommended ICU admission - when one of two major criteria (the need for invasive mechanical ventilation or vasopressors) or three of nine minor criteria are fulfilled. ${ }^{1}$ The minor criteria included variables in the CURB-65 score except age, hypoxaemia, multilobar infiltrates, leucopenia, thrombocytopenia and hypothermia. In the first ever study of these IDSA/ATS guidelines, Liapikou and colleagues were able to validate the major but not the minor criteria. ${ }^{6}$ Yet, while fulfilment of the major criteria will obviously necessitate ICU admission, validation of the minor criteria-which, when present, often create a dilemma on where to place the patient-is arguably more important.

We therefore conducted this study with the aim of assessing the predictive characteristics of the IDSA/ATS minor criteria for hospital mortality and ICU admission in comparison with the PSI and the CURB-65 scores.

\section{METHODS}

\section{Study population}

From January 2004 to December 2007 we prospectively recorded all adult admissions into our 1000-bed university hospital for CAP onto an electronic database. CAP was defined as an acute infection of the pulmonary parenchyma associated with an acute infiltrate on the chest radiograph with two or more symptoms including fever $\left(\geqslant 38^{\circ} \mathrm{C}\right)$, hypothermia $\left(<36^{\circ} \mathrm{C}\right)$, rigors, sweats, new cough or change in colour of respiratory secretions, chest discomfort or dyspnoea. Patients who were hospitalised within 14 days before the onset of symptoms or discharged home from the emergency department, immunocompromised patients (with HIV infection or haematological malignancies, undergoing chemotherapy, or on steroids equivalent to at least $10 \mathrm{mg} /$ day prednisolone for a month) and patients who were subsequently diagnosed with tuberculosis were excluded. As the key focus of this study is the IDSA/ATS minor criteria, patients who fulfilled any IDSA/ATS major criteria for severe CAP on presentation at the emergency department (ie, the need for invasive ventilation or vasopressors) were also excluded. 


\section{Clinical management}

During the study period, patients with CAP were admitted to a general ward under the care of respiratory physicians. After office hours the patients were clerked by the general medicine team on call. The nurse-to-patient ratio was one staff nurse and one assistant nurse to 12 patients, and monitoring of parameters was performed 1-6-hourly as needed. The 2001 ATS guidelines were applied and patients were discharged when they reached clinical stability and became afebrile. ${ }^{7}$ Admission to the ICU was left to the discretion of the attending physicians in the emergency department or the general ward. This was a closed medical ICU with a nurse-to-patient ratio of 1:2 and run $24 \mathrm{~h}$ by respiratory physicians who were also accredited as intensivists. Management was modelled after the Surviving Sepsis Campaign guidelines. ${ }^{8}$

\section{Data collection}

At the end of the study period, 12 research nurses under the close supervision of three investigators (JP, NWA, KCS) collected the following data via medical record review using a standardised data collection form: demographics (age, sex, nursing home residence), comorbid illnesses (heart failure, cerebrovascular, neoplastic, renal or liver diseases), the first available physical examination findings (mental status, pulse, respiratory rate, blood pressure, temperature), laboratory findings (blood urea nitrogen, glucose, sodium, haematocrit, white blood cell and platelet count, arterial oxygen tension $\left(\mathrm{PaO}_{2}\right)$ or oxygen saturation with the fraction of inspired oxygen $\left(\mathrm{FiO}_{2}\right)$, arterial $\mathrm{pH}$ ) and radiological findings (pleural effusion, unilobar

Table 1 Baseline characteristics of patients $(n=1242)$

\begin{tabular}{|c|c|}
\hline Characteristic & No $(\%)$ patients* \\
\hline \multicolumn{2}{|l|}{ Demographics } \\
\hline Mean (SD) age (years) & $65.7(20.1)$ \\
\hline Age $>50$ years & 967 (77.9) \\
\hline Age $\geqslant 65$ years & $759(61.1)$ \\
\hline Female sex & $481(38.7)$ \\
\hline Nursing home resident & $153(12.3)$ \\
\hline \multicolumn{2}{|l|}{ Comorbid illnesses } \\
\hline Heart failure & $201(16.2)$ \\
\hline Cerebrovascular disease & $341(27.5)$ \\
\hline Neoplastic disease & $81(6.5)$ \\
\hline Renal disease & $131(10.5)$ \\
\hline Liver disease & $20(1.6)$ \\
\hline \multicolumn{2}{|l|}{ Physical examination findings } \\
\hline Altered mental status & $221(17.8)$ \\
\hline Pulse $\geqslant 125 / \mathrm{min}$ & $174(14.0)$ \\
\hline Respiratory rate $\geqslant 30 / \mathrm{min}$ & $80(6.4)$ \\
\hline Systolic blood pressure $<90 \mathrm{~mm} \mathrm{Hg}$ & $84(6.8)$ \\
\hline Diastolic blood pressure $\leqslant 60 \mathrm{~mm} \mathrm{Hg}$ & $373(30.0)$ \\
\hline Temperature $<35^{\circ} \mathrm{C}$ or $\geqslant 40^{\circ} \mathrm{C}$ & $33(2.7)$ \\
\hline \multicolumn{2}{|l|}{ Laboratory and radiological findings } \\
\hline $\mathrm{BUN} \geqslant 11 \mathrm{mmol} / \mathrm{l}$ & $260(20.9)$ \\
\hline BUN $>7 \mathrm{mmol} / \mathrm{l}$ & $482(38.8)$ \\
\hline Glucose $\geqslant 14 \mathrm{mmol} / \mathrm{l}$ & $112(9.0)$ \\
\hline Haematocrit $<30 \%$ & $150(12.1)$ \\
\hline Sodium $<130 \mathrm{mmol} / \mathrm{l}$ & $181(14.6)$ \\
\hline $\mathrm{PaO}_{2}<60 \mathrm{~mm} \mathrm{Hg}$ or $\mathrm{SaO}_{2}<90 \%$ & $285(22.9)$ \\
\hline Arterial $\mathrm{pH}<7.35$ & $92(7.4)$ \\
\hline Pleural effusion & $265(21.3)$ \\
\hline
\end{tabular}

*Data were complete for all patients except the following variables: BUN $10.7 \%$ missing), glucose $\left(10.5 \%\right.$ missing), sodium $(0.6 \%$ missing $), \mathrm{PaO}_{2}$ or $\mathrm{SaO}_{2}(2.4 \%$ missing), arterial $\mathrm{pH}(73.6 \%$ missing).

$\mathrm{BUN}$, blood urea nitrogen; $\mathrm{PaO}_{2}$, arterial oxygen tension; $\mathrm{SaO}_{2}$, oxygen saturation. versus multilobar infiltrates) at the emergency department, and the use of invasive ventilation and vasopressors in the ICU. The principal investigator (JP) reviewed every form and medical record to ensure accuracy. These data were used to determine the IDSA/ATS minor criteria for severe CAP, the PSI and the CURB-65 score.

The primary and secondary outcome measures were all-cause hospital mortality and admission to the ICU, respectively.

\section{Data analyses}

Hospital mortality was classified by the number of IDSA/ATS minor criteria present. We calculated the sensitivity, specificity, positive (PPV) and negative (NPV) predictive values, relative risk and the discriminatory power using the areas under the receiver operating characteristic (ROC) curves of these criteria to predict hospital mortality. These characteristics were compared with those of the PSI and the CURB-65 score. High-risk patients were defined using commonly accepted classifications (IDSA/ATS minor criteria $\geqslant 3$, PSI classes IV and V and CURB-65 score $\geqslant 3$ ) and we evaluated the outcomes of patients with discordant classifications using these rules.

After excluding patients with orders to withhold lifesustaining treatment, the above analyses were repeated for ICU admission. Focusing on patients with three or more IDSA/ ATS minor criteria, we compared the baseline characteristics, severity and hospital mortality of those with and without ICU admission using the $\chi^{2}$ test and the Student $t$ test. Patients who were first sent to the general ward before ICU transfer were defined as having a delayed ICU admission. We entered the presence of a delay into a logistic regression model to assess its effect on mortality, and included the number of PSI points into the model to account for the overall disease severity because it incorporates patient demographics, chronic conditions and acute parameters.

The Bonferroni correction was used for multiple comparisons and a $p$ value of $<0.05$ was considered statistically significant. The statistical software SPSS Version 15.0 (SPSS, Chicago, Illinois, USA) was used for analyses.

\section{RESULTS}

\section{Study population}

During the study period 1310 patients were admitted to the hospital with CAP, of which 68 were excluded because they immediately fulfilled the IDSA/ATS major criteria for severe CAP (ie, they were invasively ventilated and/or started on vasopressors in the emergency department). The baseline characteristics of the remaining 1242 patients are shown in table 1.

\section{Hospital mortality}

Table 2 describes the predictive characteristics of the individual IDSA/ATS minor criteria for hospital mortality. While each criterion had relatively high specificity and NPV, hypoxaemia, multilobar infiltrates, confusion and a high blood urea nitrogen had higher sensitivity and specificity.

Overall, the hospital mortality was $14.7 \%$. Mortality increased with the number of IDSA/ATS minor criteria present (table 3 ) and rose sharply from $0.9 \%, 1.5 \%$ and $10.8 \%$, respectively, for patients with none, one and two minor criteria to $35.2 \%$ for patients with three minor criteria. Altogether, 330 $(26.6 \%)$ patients had at least three minor criteria.

The area under the ROC curve (fig 1) for the prediction of hospital mortality using the IDSA/ATS minor criteria was 0.88 
Table 2 Prediction of hospital mortality by the individual IDSA/ATS minor criteria

\begin{tabular}{|c|c|c|c|c|c|c|}
\hline Criterion & No (\%) patients & $\begin{array}{l}\text { Sensitivity } \\
\text { (\%) }\end{array}$ & $\begin{array}{l}\text { Specificity } \\
(\%)\end{array}$ & PPV (\%) & NPV (\%) & RR (95\% CI) \\
\hline Respiratory rate $\geqslant 30 / \mathrm{min}$ & $80(6.4)$ & 19.7 & 95.8 & 45.0 & 87.3 & 3.56 (2.67 to 4.73 ) \\
\hline $\mathrm{PaO}_{2} / \mathrm{FiO}_{2} \leqslant 250 \mathrm{~mm} \mathrm{Hg}$ & $296(23.8)$ & 70.5 & 84.2 & 43.6 & 94.3 & $7.64(5.72$ to 10.20$)$ \\
\hline Multilobar infiltrates & $480(38.6)$ & 71.6 & 67.0 & 27.3 & 93.2 & $4.00(2.96$ to 5.40$)$ \\
\hline Confusion & $221(17.8)$ & 57.4 & 89.0 & 47.5 & 92.4 & 6.22 (4.82 to 8.02 ) \\
\hline $\mathrm{BUN}>7 \mathrm{mmol} / \mathrm{l}$ & $482(38.8)$ & 73.2 & 67.1 & 27.8 & 93.6 & 4.31 (3.17 to 5.86$)$ \\
\hline WBC $<4000$ & $46(3.7)$ & 9.3 & 97.3 & 37.0 & 86.1 & 2.66 (1.78 to 3.98$)$ \\
\hline Platelet $<100000$ & $34(2.7)$ & 5.5 & 97.7 & 29.4 & 85.7 & 2.05 (1.20 to 3.52$)$ \\
\hline Temperature $<36^{\circ} \mathrm{C}$ & $38(3.1)$ & 9.8 & 98.1 & 47.4 & 86.3 & 3.46 (2.40 to 4.97$)$ \\
\hline Hypotension & $376(30.3)$ & 48.1 & 72.8 & 23.4 & 89.0 & 2.13 (1.64 to 2.78$)$ \\
\hline
\end{tabular}

$\mathrm{BUN}$, blood urea nitrogen; ; $\mathrm{Cl}$, confidence interval; $\mathrm{FiO}_{2}$, fraction of inspired oxygen; NPV, negative predictive value; $\mathrm{PaO}_{2}$, arterial oxygen tension; PPV, positive predictive value; $\mathrm{RR}$, relative risk; WBC, white blood cell.

(95\% confidence interval (CI) 0.86 to 0.91 ), which was higher than that of the PSI (0.86 (95\% CI 0.83 to 0.88$)$ ) and the CURB65 score (0.82 (95\% CI 0.78 to 0.85), $\mathrm{p}<0.05$ after Bonferroni correction for each pairwise comparison).

The application of a threshold of three or more minor criteria as suggested by IDSA/ATS to define severe CAP resulted in a sensitivity, specificity, PPV and NPV of $81.4 \%, 82.9 \%, 45.2 \%$ and $96.3 \%$ for hospital mortality (table 4 ). The corresponding values for a PSI class of IV or higher were $96.2 \%, 57.9 \%, 28.3 \%$ and $98.9 \%$ respectively, while the corresponding values for a CURB-65 score of 3 or higher were $61.2 \%, 83.3 \%, 38.8 \%$ and $92.5 \%$, respectively. The IDSA/ATS minor criteria, PSI class and CURB-65 score classified $26.6 \%, 50.1 \%$ and $23.3 \%$ as severe CAP, respectively.

Table 5 describes the outcomes of patients with discordant classifications into high-risk versus low-risk CAP using the various clinical prediction rules. The IDSA/ATS minor criteria classified as severe 99 patients who were defined as low-risk by the CURB-65 score (43.4\% of these patients died). The PSI class classified as severe 324 patients who were defined as low-risk by the IDSA/ATS minor criteria (only $9.6 \%$ of these patients died). Using a threshold of two instead of three minor IDSA/ATS criteria to define severe CAP improved the concordance with the PSI class but also decreased the PPV of the criteria.

\section{ICU admission}

To evaluate the predictive characteristics of the IDSA/ATS minor criteria for ICU admission, 225 patients with orders to withhold life-sustaining treatment were excluded. In the remaining 1017 patients, the area under the ROC curve (fig 2) for the prediction of ICU admission using the IDSA/ATS minor criteria was 0.85 (95\% CI 0.81 to 0.88 ), which was higher than that of the PSI class $(0.75,95 \%$ CI 0.71 to 0.79$)$ and CURB-65 score $(0.68,95 \%$ CI 0.63 to $0.72 ; \mathrm{p}<0.05$ after Bonferroni correction for each pairwise comparison).

Table 3 Hospital mortality and the IDSA/ATS minor criteria

\begin{tabular}{lcc}
\hline No of criteria & No $(\%)$ patients & No $(\%)$ deaths \\
\hline 0 & $346(27.9)$ & $3(0.9)$ \\
1 & $325(26.2)$ & $5(1.5)$ \\
2 & $241(19.4)$ & $26(10.8)$ \\
3 & $165(13.3)$ & $58(35.2)$ \\
4 & $97(7.8)$ & $41(42.3)$ \\
5 & $47(3.8)$ & $29(61.7)$ \\
6 & $19(1.5)$ & $19(100.0)$ \\
7 & $2(0.2)$ & $2(100.0)$ \\
Total & $1242(100.0)$ & $183(14.7)$ \\
\hline
\end{tabular}

A threshold of three or more IDSA/ATS minor criteria (172 patients) resulted in a sensitivity, specificity, PPV and NPV of $58.3 \%, 90.6 \%, 52.9 \%$ (91 patients) and $92.3 \%$ for ICU admission. The corresponding values for a PSI class of IV or higher were $72.4 \%, 65.3 \%, 27.4 \%$ and $92.9 \%$ respectively, while the corresponding values for a CURB-65 score of 3 or higher were $26.3 \%, 88.3 \%, 28.9 \%$ and $86.9 \%$, respectively.

Among the 172 patients with three or more IDSA/ATS minor criteria, 91 were admitted to the ICU, of which 75 were subsequently invasively ventilated and 67 put on vasopressors. These patients were younger (63.4 vs 73.7 years, $p<0.001$ ), included fewer nursing home residents $(1.1 \%$ vs $28.4 \%$, $\mathrm{p}<0.001)$ and had higher PSI points (129 (32) vs 118 (34), $\mathrm{p}=0.04)$ and mortality $(45.1 \%$ vs $0 \%, \mathrm{p}<0.001)$ than the remaining 81 non-ICU patients. Fifty-five patients with delayed ICU admission had similar PSI points (126 (27) vs 132 (39), $\mathrm{p}=0.42)$ but higher mortality $(54.5 \%$ vs $30.6 \%, p=0.03)$ than 36 patients without delay. In a logistic regression model which incorporated this delay and the number of PSI points, delayed

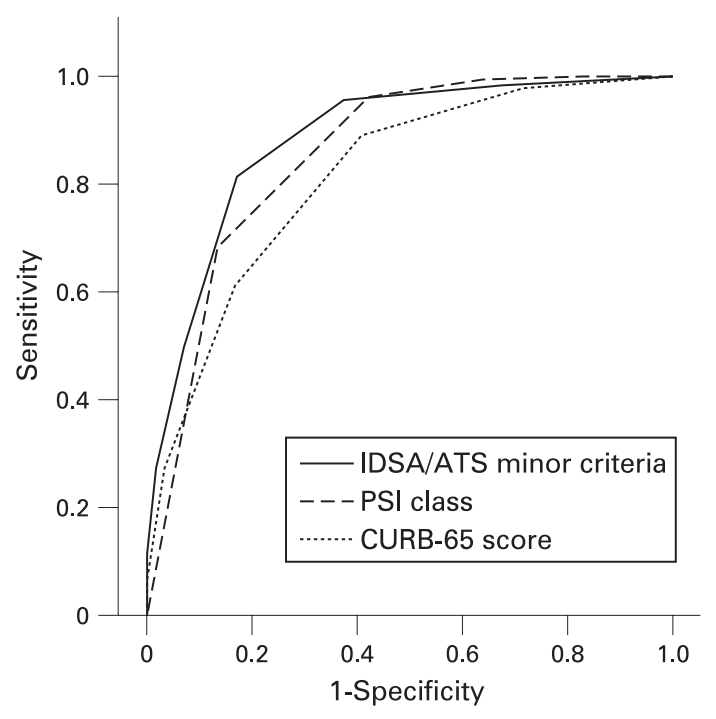

Figure 1 Receiver operating characteristic curves for hospital mortality for the Infectious Diseases Society of America/American Thoracic Society (IDSA/ATS) minor criteria, Pneumonia Severity Index (PSI) class and CURB-65 (confusion, urea nitrogen, respiratory rate, blood pressure) score. The areas under the receiver operating characteristic curves were 0.88 (95\% Cl 0.86 to 0.91$)$ for the IDSA/ATS minor criteria, $0.86(95 \% \mathrm{Cl}$ 0.83 to 0.88$)$ for the PSI class and $0.82(95 \% \mathrm{Cl} 0.78$ to 0.85$)$ for the CURB-65 score $(p<0.05$ after Bonferroni correction for each pairwise comparison). 
Table 4 Prediction of hospital mortality by the IDSA/ATS minor criteria

\begin{tabular}{|c|c|c|c|c|c|c|}
\hline Rule & $\operatorname{ROC}(95 \% \mathrm{CI})$ & Sensitivity (\%) & Specificity (\%) & PPV (\%) & NPV (\%) & RR (95\% CI) \\
\hline \multicolumn{7}{|c|}{ IDSA/ATS minor criteria } \\
\hline$\geqslant 1$ & $0.65(0.62$ to 0.69$)$ & 98.4 & 32.4 & 20.1 & 99.1 & 23.17 (7.45 to 72.03$)$ \\
\hline$\geqslant 2$ & 0.79 (0.76 to 0.82$)$ & 95.6 & 62.6 & 30.6 & 98.8 & $25.71(12.77$ to 51.75$)$ \\
\hline$\geqslant 3^{*}$ & 0.82 (0.79 to 0.86$)$ & 81.4 & 82.9 & 45.2 & 96.3 & 12.11 (8.53 to 17.20$)$ \\
\hline$\geqslant 4$ & $0.71(0.67$ to 0.76$)$ & 49.7 & 93.0 & 55.2 & 91.5 & 6.46 (5.08 to 8.20$)$ \\
\hline$\geqslant 5$ & 0.63 (0.58 to 0.68$)$ & 27.3 & 98.3 & 73.5 & 88.7 & $6.49(5.24$ to 8.04$)$ \\
\hline$\geqslant 6$ & $0.56(0.51$ to 0.61$)$ & 11.5 & 100.0 & 100.0 & 86.7 & 7.54 (6.53 to 8.70$)$ \\
\hline 7 & $0.51(0.46$ to 0.55$)$ & 1.1 & 100.0 & 100.0 & 85.4 & 6.85 (5.99 to 7.84$)$ \\
\hline \multicolumn{7}{|c|}{ PSI class } \\
\hline$\geqslant \| 1$ & $0.59(0.55$ to 0.63$)$ & 100.0 & 17.0 & 17.2 & 100.0 & Not applicable $\dagger$ \\
\hline$\geqslant|I|$ & $0.68(0.64$ to 0.71$)$ & 99.5 & 36.2 & 21.2 & 99.7 & 81.46 (11.46 to 579.23$)$ \\
\hline$\geqslant \mathrm{IV}^{*}$ & $0.77(0.74$ to 0.80$)$ & 96.2 & 57.9 & 28.3 & 98.9 & 25.06 (11.87 to 52.91$)$ \\
\hline V & $0.77(0.73$ to 0.82$)$ & 68.3 & 86.6 & 46.8 & 94.1 & 7.87 (5.95 to 10.42$)$ \\
\hline \multicolumn{7}{|c|}{ CURB-65 score } \\
\hline$\geqslant 1$ & 0.63 (0.59 to 0.67$)$ & 97.8 & 28.4 & 19.1 & 98.7 & 14.57 (5.45 to 38.91$)$ \\
\hline$\geqslant 2$ & $0.74(0.71$ to 0.78$)$ & 89.1 & 59.2 & 27.4 & 96.9 & 8.86 (5.65 to 13.91$)$ \\
\hline$\geqslant 3^{*}$ & $0.72(0.68$ to 0.77$)$ & 61.2 & 83.3 & 38.8 & 92.5 & 5.20 (3.98 to 6.79$)$ \\
\hline$\geqslant 4$ & $0.62(0.57$ to 0.67$)$ & 27.3 & 96.7 & 58.8 & 88.5 & 5.12 (4.03 to 6.50$)$ \\
\hline 5 & $0.53(0.49$ to 0.58$)$ & 6.6 & 100.0 & 100.0 & 86.1 & $7.19(6.26$ to 8.27$)$ \\
\hline
\end{tabular}

ATS, American Thoracic Society; Cl, confidence interval; CURB, confusion, urea nitrogen, respiratory rate, blood pressure; IDSA, Infectious Diseases Society of America; NPV, negative predictive value; PPV, positive predictive value; PSI, Pneumonia Severity Index; ROC, receiver operating characteristic area under the curve; RR, relative risk.

*Widely accepted thresholds to define low-risk versus high-risk patients.

$\dagger$ Not applicable owing to negative predictive value of $100 \%$.

ICU admission was the sole independent predictor of mortality (odds ratio $3.13,95 \%$ CI 1.23 to $7.87, p=0.02$ ). The median time spent in the ward before ICU transfer was $12.0 \mathrm{~h}$ (interquartile range 4.3-24.0) for the delayed group.

\section{DISCUSSION}

Our findings show that the 2007 IDSA/ATS minor criteria for severe CAP had greater discriminatory power, as reflected by the area under the ROC curve, for the prediction of both hospital mortality and ICU admission than the better established PSI and CURB-65 score. The IDSA/ATS minor criteria were markedly more specific than the PSI and markedly more sensitive than the CURB-65 score in these predictions.

The rationale for the introduction of the IDSA/ATS criteria for severe CAP is clear: no widely accepted definition of severe CAP exists, and previous clinical prediction rules were suboptimal predictors of both death and ICU admission. ${ }^{15}$ The PSI is cumbersome $e^{9-11}$ and was originally designed to identify low-risk patients. ${ }^{2}$ Because it includes variables which do not reflect the current illness severity, otherwise well patients with stable co-morbidities are often assigned to PSI classes IV and V. ${ }^{4}$ The CURB-65 score is easier to use ${ }^{910}$ but lacks important variables such as oxygenation and is insensitive for predicting mortality. ${ }^{12}$ Consistent with previous studies that have compared the two rules, ${ }^{13-17}$ we found that the PSI had a poor specificity of $57.9 \%$ while the CURB-65 score had a poor sensitivity of $61.2 \%$ for mortality.

In our study the IDSA/ATS minor criteria for severe CAP appeared to bridge the gap between the PSI and the CURB-65 score. Using ROC curve analysis, the optimal threshold for the prediction of hospital mortality was the fulfilment of three of nine minor criteria, just as suggested in the IDSA/ATS guidelines. This threshold resulted in a sensitivity of $81.4 \%$ and a specificity of $82.9 \%$ for hospital mortality. The area under the curve was higher for the IDSA/ATS minor criteria (0.88) than the PSI and the CURB-65 score for mortality prediction. When discordant classifications were compared, we found a considerable benefit of using the minor criteria over the CURB-65 score for predicting mortality, and only a marginal benefit of using the PSI over the minor criteria which is associated with overlabelling of many patients as severe.

Table 5 Discordant predictions of hospital mortality from three clinical prediction rules

\begin{tabular}{lllcc}
\hline & PSI class $\geqslant$ IV & CURB-65 $\geqslant \mathbf{3}$ & No $(\%)$ patients & No (\%) deaths \\
\hline IDSA/ATS $\geqslant 3$ & & & & \\
+ & - & NA & $32(2.6)$ & $4(12.5)$ \\
- & + & NA & $324(26.1)$ & $31(9.6)$ \\
+ & NA & - & $99(8.0)$ & $43(43.4)$ \\
- & NA & + & $58(4.7)$ & $6(10.3)$ \\
IDSA $/$ ATS $\geqslant 2$ & & & & $6(5.1)$ \\
+ & - & NA & $118(9.5)$ & $7(4.1)$ \\
- & + & NA & $169(13.6)$ & $63(22.3)$ \\
+ & NA & - & $282(22.7)$ & $0(\mathrm{NA})$ \\
- & NA & + & $0(0)$ & \\
\hline
\end{tabular}

ATS, American Thoracic Society; CURB, confusion, urea nitrogen, respiratory rate, blood pressure; IDSA, Infectious Diseases Society of America; PSI, Pneumonia Severity Index; NA, not applicable. 


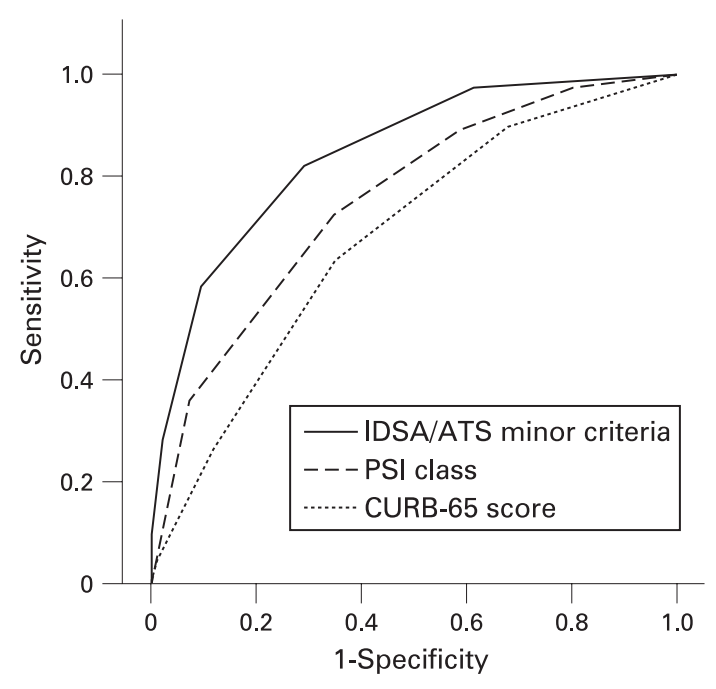

Figure 2 Receiver operating characteristic curves for admission to the intensive care unit for the Infectious Diseases Society of America/ American Thoracic Society (IDSA/ATS) minor criteria, Pneumonia Severity Index (PSI) class and CURB-65 (confusion, urea nitrogen, respiratory rate, blood pressure) score. The areas under the receiver operating characteristic curves were 0.85 ( $95 \% \mathrm{CI} 0.81$ to 0.88 ) for the IDSA/ATS minor criteria, 0.75 (95\% CI 0.71 to 0.79 ) for the PSI class and 0.68 (95\% Cl 0.63 to 0.72 ) for the CURB-65 score $(p<0.05$ after Bonferroni correction for each pairwise comparison).

The 2007 IDSA/ATS guidelines recommended that ICU admission be considered for patients who fulfilled three or more minor criteria. ${ }^{1}$ The fact that almost half $(45.2 \%)$ of such patients died in our study lends support to this recommendation. However, although the minor criteria had a high NPV of 92.3\% for predicting ICU admission, the PPV was lower at $52.9 \%$, even when patients with orders to withhold lifesustaining treatment were excluded. This problem is consistently seen in other clinical prediction rules. ${ }^{52-14} 1819$ Nevertheless, our findings reveal that, just as in mortality, the IDSA/ATS minor criteria were more specific than the PSI, more sensitive than the CURB-65 score and had the greatest overall discriminatory power for predicting ICU admission.

What is the usefulness of a clinical prediction rule for severe CAP? A rule such as the IDSA/ATS criteria with a relatively high sensitivity and specificity for predicting mortality can guide clinical decisions on which patients require rapid escalation to resuscitation and management bundles for severe sepsis and/or respiratory failure, ${ }^{20}$ followed by direct admission to the ICU. Such decisions should not be taken lightly. Admission to the ICU for low-risk patients will drive up health care costs unnecessarily, ${ }^{5}$ while failure to or delay in admitting patients with truly severe CAP to the ICU may lead to increased mortality. ${ }^{21}$ The delay faced by $60 \%$ of our ICU patients who were labelled as severe CAP based on the IDSA/ATS minor criteria, but were first transferred from the emergency department to the general ward, was an independent predictor of mortality. Such a delay is not uncommon in many centres, ${ }^{19}$ and underscores the arbitrary nature of the decision for ICU admission in the absence of validated clinical prediction rules. This is especially true in situations where patients may not need emergency invasive ventilation or vasopressors (ie, the IDSA/ ATS major criteria), but rather fulfil some of the minor criteria. Indeed, older studies have shown an extreme variation of ICU admission rates from $3 \%$ to $39 \% .{ }^{22} 23$
In the only other published study on the IDSA/ATS criteria, Liapikou and colleagues evaluated 1924 patients after excluding 178 patients with the major criteria. ${ }^{6}$ The number of minor criteria was related to mortality, and a threshold of two or more minor criteria resulted in a sensitivity and specificity of $64 \%$ and $72 \%$, respectively, for ICU admission. There are several differences between this study and ours. First, while we found that each minor criterion was predictive of mortality, Liapikou and colleagues used serum creatinine measurements in place of blood urea nitrogen and could not demonstrate an association between hypotension, thrombocytopenia and multilobar involvement and mortality. This is surprising as the IDSA/ATS guidelines had chosen these variables based on prior evidence. ${ }^{13} 192425$ Second, patients with severe CAP who were not admitted to the ICU because of orders not to intubate were included in their analyses. ${ }^{26}$ This will adversely affect the predictive indices of the IDSA/ATS criteria for ICU admission. Third, while we emphasise that any delay in ICU admission when indicated may increase mortality, Liapikou and colleagues highlighted their findings that the number of minor criteria present did not predict any mortality reduction from ICU admission. These findings are difficult to interpret. Their patients were less sick than ours: $11.4 \%$ of their patients compared with $26.6 \%$ of ours fulfilled the IDSA/ATS minor criteria, with a hospital mortality of $10.5 \%$ versus $45.2 \%$. The benefits of ICU admission are understandably diluted in less sick patients. Moreover, only 47 of their patients compared with 91 of ours who fulfilled the minor criteria were admitted to the ICU. Such small sample sizes limit the interpretation of any subgroup analyses on the impact of ICU admission on mortality.

The limitations of our study must be acknowledged. First, although we prospectively recorded all cases of CAP during the study period, the data collection was subsequently performed using medical record review. Nevertheless, we made all attempts to ensure data accuracy with standardised data forms and subsequent checks by the principal investigator (JP) for every case. Second, the hospital mortality of our cohort of $14.7 \%$ which, though similar to the mortality reported by some investigators, ${ }^{14}$ was higher than that reported by others. ${ }^{2}{ }^{2} 151719$ Several factors may account for this. Different forms of mortality were used in these studies. Given the logistical difficulties of ensuring close follow-up after hospital discharge, we chose hospital instead of 28-30-day mortality as the primary outcome. Since the former may be influenced by discharge practices, we followed recommended criteria for hospital discharge. The similar baseline characteristics of our patients to the original PSI and CURB-65 cohorts suggest that our findings may reasonably be extrapolated to most CAP populations. ${ }^{23}$ Even so, it is known that clinical prediction rules should be recalibrated to local settings. ${ }^{27}$ Hence, future multicentre studies should be performed to confirm the generalisability of the findings of our single-centre study. Third, several other clinical prediction rules which focus on severe CAP have emerged in recent years, including the PIRO score, the SMART-COP score and the SCAP prediction rule. ${ }^{12} 162829$ Comparisons of these rules with the IDSA/ATS criteria will now be required.

In conclusion, our findings support the use of the IDSA/ATS minor criteria to predict hospital mortality and guide escalation of care with prompt ICU admission in inpatients with CAP who do not require emergency invasive mechanical ventilation or vasopressors. The IDSA/ATS minor criteria had a greater discriminatory power for mortality and ICU admission than 
the better established PSI and CURB-65 score, and help bridged the gap between the low specificity of the PSI and the low sensitivity of the CURB-65 score for these important clinical outcomes.

Acknowledgements: The authors sincerely thank the following research nurses from the School of Health Sciences, Ngee Ann Polytechnic, Singapore: Carol Yeo, Dephine Ho Ke Chi; Jason Tan Meng Thong, Jeany Teo Gim Yen, Jolene Ho Suet Yen, Leo Wan Ling, Loh Chuan Linn, Nur Faezah Bte Johari, Nurasyikin Bte Abdullah, Nurhidayah Bte Mohameds, Shirley Kwek and Tee Ning.

Funding: None.

Competing interests: None.

This study was approved by our institutional review board.

\section{REFERENCES}

1. Mandell LA, Wunderink RG, Anzueto A, et al. Infectious Diseases Society of America/American Thoracic Society consensus guidelines on the management of community-acquired pneumonia in adults. Clin Infect Dis 2007;44(Suppl 2):S27-72.

2. Fine MJ, Auble TE, Yealy DM, et al. A prediction rule to identify low-risk patients with community-acquired pneumonia. N Engl J Med 1997;336:243-50.

3. Lim WS, van der Eerden MM, Laing $R$, et al. Defining community acquired pneumonia severity on presentation to hospital: an international derivation and validation study. Thorax 2003:58:377-82.

4. Suchyta MR, Dean NC, Narus S, et al. Effects of a practice guideline for communityacquired pneumonia in an outpatient setting. Am J Med 2001;110:306-9.

5. Angus DC, Marrie TJ, Obrosky DS, et al. Severe community-acquired pneumonia: use of intensive care services and evaluation of American and British Thoracic Society diagnostic criteria. Am J Respir Crit Care Med 2002;166:717-23.

6. Liapikou A, Ferrer M, Polverino E, et al. Severe community-acquired pneumonia: validation of the Infectious Diseases Society of America/American Thoracic Society guidelines to predict an intensive care unit admission. Clin Infect Dis 2009;48:377-85.

7. Niederman MS, Mandell LA, Anzueto A, et al. Guidelines for the management of adults with community-acquired pneumonia. Diagnosis, assessment of severity, antimicrobial therapy, and prevention. Am J Respir Crit Care Med 2001;163:1730-54.

8. Dellinger RP, Carlet JM, Masur $\mathrm{H}$, et al. Surviving Sepsis Campaign guidelines for management of severe sepsis and septic shock. Crit Care Med 2004;32:858-73.

9. Niederman MS, Feldman C, Richards GA. Combining information from prognostic scoring tools for CAP: an American view on how to get the best of all worlds. Eur Respir J 2006;27:9-11.

10. Ewig S, Torres A, Woodhead M. Assessment of pneumonia severity: a European perspective. Eur Respir J 2006;27:6-8.

11. Maxwell DJ, Mclntosh KA, Pulver LK, et al. Empiric management of communityacquired pneumonia in Australian emergency departments. Med J Aust 2005; 183:520-4.

12. Charles PG, Wolfe R, Whitby M, et al. SMART-COP: a tool for predicting the need for intensive respiratory or vasopressor support in community-acquired pneumonia. Clin Infect Dis 2008;47:375-84.
13. Buising $\mathbf{K L}$, Thursky KA, Black JF, et al. A prospective comparison of severity scores for identifying patients with severe community acquired pneumonia: reconsidering what is meant by severe pneumonia. Thorax 2006;61:419-24.

14. Ananda-Rajah MR, Charles PG, Melvani S, et al. Comparing the pneumonia severity index with CURB-65 in patients admitted with community acquired pneumonia. Scand J Infect Dis 2008;40:293-300.

15. Aujesky D, Auble TE, Yealy DM, et al. Prospective comparison of three validated prediction rules for prognosis in community-acquired pneumonia. Am J Med 2005; 118:384-92.

16. Espana PP, Capelastegui A, Gorordo I, et al. Development and validation of a clinical prediction rule for severe community-acquired pneumonia. Am J Respir Crit Care Med 2006;174:1249-56

17. Man SY, Lee N, Ip M, et al. Prospective comparison of three predictive rules for assessing severity of community-acquired pneumonia in Hong Kong. Thorax 2007;62:348-53.

18. Ewig S, Ruiz M, Mensa J, et al. Severe community-acquired pneumonia. Assessment of severity criteria. Am J Respir Crit Care Med 1998;158:1102-8.

19. Ewig S, de Roux A, Bauer T, et al. Validation of predictive rules and indices of severity for community acquired pneumonia. Thorax 2004;59:421-7.

20. Dellinger RP, Levy MM, Carlet JM, et al. Surviving Sepsis Campaign: international guidelines for management of severe sepsis and septic shock: 2008. Crit Care Med 2008;36:296-327.

21. Leroy 0, Santre C, Beuscart C, et al. A five-year study of severe community-acquired pneumonia with emphasis on prognosis in patients admitted to an intensive care unit. Intensive Care Med 1995;21:24-31.

22. Fang GD, Fine $\mathrm{M}$, Orloff $\mathrm{J}$, et al. New and emerging etiologies for communityacquired pneumonia with implications for therapy. A prospective multicenter study of 359 cases. Medicine (Baltimore) 1990;69:307-16.

23. Ortqvist A, Sterner G, Nilsson JA. Severe community-acquired pneumonia: factors influencing need of intensive care treatment and prognosis. Scand J Infect Dis 1985;17:377-86.

24. Mortensen EM, Coley CM, Singer DE, et al. Causes of death for patients with community-acquired pneumonia: results from the Pneumonia Patient Outcomes Research Team cohort study. Arch Intern Med 2002;162:1059-64.

25. Laterre PF, Garber G, Levy H, et al. Severe community-acquired pneumonia as a cause of severe sepsis: data from the PROWESS study. Crit Care Med 2005;33:95261.

26. Mandell LA. Severe community-acquired pneumonia (CAP) and the Infectious Diseases Society of America/American Thoracic Society CAP guidelines prediction rule: validated or not. Clin Infect Dis 2009;48:386-8.

27. Schuetz $\mathbf{P}$, Koller $\mathrm{M}$, Christ-Crain $\mathrm{M}$, et al. Predicting mortality with pneumonia severity scores: importance of model recalibration to local settings. Epidemiol Infect 2008;136:1628-37.

28. Rello J, Rodriguez A, Lisboa T, et al. PIRO score for community-acquired pneumonia: a new prediction rule for assessment of severity in intensive care unit patients with community-acquired pneumonia. Crit Care Med 2009;37:456-62.

29. Espana Yandiola PP, Capelastegui A, Quintana JM, et al. Prospective comparison of severity scores for predicting clinically relevant outcomes for patients hospitalized with community-acquired pneumonia. Chest 200913 Jan (Epub ahead of print)

\section{Save your favourite articles and useful searches}

Use the "My folders" feature to save and organise articles you want to return to quickly—saving space on your hard drive. You can also save searches, which will save you time. You will only need to register once for this service, which can be used for this journal or all BMJ Journals, including the BMJ. 